\title{
Experimental Trypanosoma cruzi infection in platelet-activating factor receptor-deficient mice
}

\author{
André Talvani a , Gilcinea Santana ${ }^{\text {a }}$, Lucíola S. Barcelos a , Satoshi Ishii ${ }^{\text {b,c }}$, Takao Shimizu ${ }^{\text {b,c }}$, \\ Álvaro J. Romanha ${ }^{\mathrm{d}}$, João S. Silva ${ }^{\mathrm{e}}$, Milena B.P. Soares ${ }^{\mathrm{f}}$, Mauro M. Teixeira ${ }^{\mathrm{a}, \mathrm{d}, *}$ \\ ${ }^{a}$ Departamento de Bioquímica e Imunologia, Instituto de Ciências Biológicas, Universidade Federal de Minas Gerais, Avenida Antônio Carlos, \\ 6627 Pampulha, 31270-901 Belo Horizonte, Minas Gerais, Brazil \\ ${ }^{b}$ Department of Biochemistry and Molecular Biology, Faculty of Medicine, The University of Tokyo, Japan \\ ${ }^{c}$ CREST of Japan Science and Technology Corporation, Tokyo, Japan \\ ${ }^{d}$ Centro de Pesquisas René Rachou, FIOCRUZ, Belo Horizonte,Brazil \\ ${ }^{e}$ Faculdade de Medicina de Ribeirão Preto, Universidade de São Paulo, Ribeirão Preto, São Paulo, Brazil \\ ${ }^{f}$ Centro de Pesquisa Gonçalo Moniz, FIOCRUZ, Salvador, Brazil
}

Received 19 December 2002; accepted 31 March 2003

\begin{abstract}
The generation of an inflammatory response driven by Trypanosoma cruzi or its subproducts appears to be essential for tissue injury and disease pathogenesis. However, this inflammatory response is also relevant in the control of $T$. cruzi replication. The lipid mediator platelet-activating factor (PAF) has been implicated in a number of pathological conditions characterized by tissue inflammation. In the present study, we aimed at evaluating the role of PAF during T. cruzi infection by using mice that were genetically deficient in the PAF receptor. We observed that infected hearts of $\mathrm{PAFR}^{--}$mice had an increased number of parasite nests, associated with a more intense inflammatory infiltrate. This was associated with greater parasitemia and lethality. When wild-type and $\mathrm{PAFR}^{-1-}$ mice were compared, there were no marked changes in the kinetics of the expression of MCP-1, RANTES, IFN- $\gamma$ and TNF- $\alpha$ in heart tissue of infected animals. Moreover, serum concentrations of TNF- $\alpha$, nitrate and parasite-specific IgM were similar in both groups of mice. In vitro, macrophages from PAFR ${ }^{-1}$ animals did not phagocytose trypomastigote forms when activated with PAF, leukotriene $\mathrm{B}_{4}$ or MCP-1 and produced less nitric oxide when infected and activated with IFN- $\gamma$. These results are consistent with the hypothesis that endogenous synthesis of PAF and activation of PAF receptors control T. cruzi replication in mice in great part via facilitation of the uptake of the parasite and consequent activation of macrophages.
\end{abstract}

(C) 2003 Éditions scientifiques et médicales Elsevier SAS. All rights reserved.

Keywords: Platelet-activating factor; Protozoan infection; Inflammation; Chemokines; TNF- $\alpha$; Knockout

\section{Introduction}

Chagas' disease, a common cause of congestive heart failure and sudden death in South and Central America, is caused by a hemoflagellate parasite, Trypanosoma cruzi, which is widely distributed in this geographic area [1,2]. The generation of an inflammatory response driven by T. cruzi or its subproducts appears to be essential for tissue injury and disease pathogenesis $[3,4]$. In addition to parasite-driven inflammation, an autoimmune component may also play a role in the tissue damage during the chronic stages of the

\footnotetext{
* Corresponding author.

Tel.: +55-31-3499-2651; fax: +55-31-3441-5963

E-mail address: mmtex@icb.ufmg.br (M.M. Teixeira).
}

disease, especially in cardiac tissues [5-7]. The inflammation observed in infected tissues is characterized by the infiltration of $\mathrm{CD}^{+}$and $\mathrm{CD}^{+} \mathrm{T}$ cells and macrophages, which appear to secrete a range of cytokines, chemokines, oxygen reactive products and other inflammatory mediators, such as platelet-activating factor $(\mathrm{PAF})$ and leukotriene $\mathrm{B}_{4}\left(\mathrm{LTB}_{4}\right)$ [3,8-13]. Although inflammation determines tissue damage, the cellular influx and mediators formed in response to parasite invasion appear to be relevant in the control of $T$. cruzi replication. The question of whether a similar set of mediators is responsible for tissue damage and defense against the parasite clearly deserves investigation.

The lipid mediator PAF (1-0-alkyl-2-acetyl-sn-glyceryl3 -phosphorocholine), is produced by a diverse number of inflammatory cells, including macrophages, neutrophils, ba- 
sophils, eosinophils, platelets and endothelial cells $[14,15]$. PAF has been implicated in a number of pathological conditions, including endotoxic shock, thrombosis, allergic reactions and a variety of other inflammatory conditions [14-16]. Studies on immunity to $T$. cruzi infection have focused on the relationship between cytokines/chemokines and production of nitric oxide (NO) and oxygen intermediates $[3,4,8,17,18]$. The involvement of other mediators, such as those derived from membrane metabolism, in immunity to $T$. cruzi has been largely ignored. More recently, our group demonstrated that PAF and another lipid mediator, $\mathrm{LTB}_{4}$, were able to induce NO and tumor necrosis factor- $\alpha$ (TNF- $\alpha$ ) synthesis in cultured T. cruzi-infected peritoneal macrophages and kill the parasite in a NO-dependent manner [12,19]. In vivo, blockade of PAF or $\mathrm{LTB}_{4}$ receptors was accompanied by higher parasitemia and lower survival of infected animals $[12,19]$.

In the present study, we aimed at evaluating the protective role of PAF during T. cruzi infection by using mice that were genetically deficient in the PAF receptor [20]. Moreover, we evaluated several aspects of the inflammatory response and parasitological indices during T. cruzi infection in an attempt to identify mechanisms involved in the protective effects of PAF in our model. We observed that infected hearts of $\mathrm{PAFR}^{-/}$mice had an increased number of parasite nests, associated with a more intense inflammatory infiltrate. This was associated with greater parasitemia and lethality. In vitro, macrophages from $\mathrm{PAFR}^{-/}$animals did not phagocytose trypomastigote forms when activated with $\mathrm{PAF}, \mathrm{LTB}_{4}$ or MCP-1 and produced less NO when infected and activated with IFN- $\gamma$. Together with our previous studies $[12,19]$, our results are consistent with the hypothesis that endogenous synthesis of PAF and activation of PAF receptors control $T$. cruzi replication in mice in great part via facilitation of the phagocytosis of the parasite and consequent activation of macrophages.

\section{Materials and methods}

\subsection{Experimental animals}

Female C57BL/6 wild-type and PAF receptor-deficient mice [20] were bred at Centro de Pesquisas Gonçalo Muniz, FIOCRUZ (Salvador, Brazil) and maintained under standard conditions in the animal house of our institution. Animals were used when $8-10$ weeks old. All procedures had prior approval from the local animal ethics committee.

\subsection{Parasites and experimental infection}

The Y strain of T. cruzi was used in all experiments. Trypomastigote forms were cultured and purified from the monkey kidney fibroblast cell line LLC-MK2 for experiments in vitro. C57BL/6 mice were infected intraperitoneally with $5 \times 10^{3}$ blood trypomastigote forms, and parasitemia was evaluated daily by counting the number of parasites in $5 \mu \mathrm{l}$ of blood from a tail vein, as previously described [21].

\subsection{Macrophage culture}

Inflammatory macrophages were harvested from the peritoneal cavity of mice $3 \mathrm{~d}$ after the injection of $1.5 \mathrm{ml}$ of $3 \%$ $(\mathrm{w} / \mathrm{v})$ sodium thioglycolate (Sigma). Cells $\left(10^{6} / \mathrm{ml}\right)$ were plated onto chamber slides in 24-well tissue culture plates and incubated for $2-4 \mathrm{~h}$ at $37{ }^{\circ} \mathrm{C}$. The non-adherent cells were removed by exhaustive washing with Hank's medium. Adherent cells were then infected at a parasite-to-cell ratio of 1:1 for $120 \mathrm{~min}$. After incubation with T. cruzi, extracellular parasites were removed by six washes with RPMI-1640 and infected macrophages were incubated at $37{ }^{\circ} \mathrm{C}$ in $5 \% \mathrm{CO}_{2}$ in the presence or absence of $50 \mathrm{U} / \mathrm{ml}$ of recombinant murine IFN- $\gamma$ (Life Technologies, Bethesda, Md.) for $48 \mathrm{~h}$. Supernatants from these infected cultured peritoneal macrophages were collected to measure $\mathrm{NO}_{2}+\mathrm{NO}_{3}\left(\mathrm{NO}_{x}\right)$ levels, as described below.

In parallel experiments, the uptake of trypomastigote forms by macrophages was evaluated in vitro [17]. Macrophages $\left(10^{6} / \mathrm{ml}\right)$ derived from the peritoneal cavity of wild-type or $\mathrm{PAFR}^{-/}$mice were plated onto glass slides that fitted 48-well plates. After washing to remove non-adherent cells, macrophages were treated with $\operatorname{PAF}\left(10^{-7} \mathrm{M}\right), \mathrm{LTB}_{4}$ $\left(10^{-6} \mathrm{M}\right)$ or MCP-1 $\left(10^{-7} \mathrm{M}\right)$ for $10 \mathrm{~min}$. Parasites were added in a 2:1 parasite:cell ratio, and $2 \mathrm{~h}$ later the extracellular trypomastigote forms were removed by washing with RPMI-1640. The macrophages were fixed with methanol and stained with Giemsa solution (1:20) in order to determine the number of intracellular amastigotes. At least 200 macrophages were analyzed on each slide, and all experiments were carried out in triplicate.

\section{4. $N O_{x}$ measurement in vivo and in vitro}

Nitrite levels in supernatants of infected macrophage cultures were determined using the Griess reaction, as an index of the NO produced [22]. To determine the levels of $\mathrm{NO}_{x}$ in vivo, blood was collected on different days before sacrifice of infected wild-type and transgenic animals. Serum was obtained from these samples, and $\mathrm{NO}_{x}$ was measured using the Griess reaction [22] after treatment of samples with nitrate reductase [23].

\subsection{TNF- $\alpha, I F N-\gamma$, RANTES and MCP-1 measurement}

Left and right ventricles from wild-type and $\mathrm{PAFR}^{-/-}$ mouse hearts were homogenized in phosphate-buffered saline (PBS) $\mathrm{pH} 7.4$, centrifuged at $1000 \mathrm{rpm}$ at $4{ }^{\circ} \mathrm{C}$ and supernatants were stored at $-70{ }^{\circ} \mathrm{C}$. The concentrations of TNF- $\alpha$, IFN- $\gamma$, MCP-1 and RANTES in cardiac extracts were evaluated by ELISA using commercially available antibodies and according to the protocol provided by the supplier (duo-set R\&D Systems).

\subsection{IgM ELISA}

Flat-bottom 96-well microtiter plates (Nunc) were coated with $100 \mu \mathrm{l} /$ well of the $T$. cruzi epimastigote antigen 
$(10 \mu \mathrm{l} / \mathrm{ml})$ at $4{ }^{\circ} \mathrm{C}$ overnight and then washed with $1 \times$ PBS (pH 7.4) containing $0.05 \%$ Tween-20 (wash buffer). Nonspecific binding sites were blocked $2 \mathrm{~h}$ with $200 \mathrm{ml} /$ well of $1 \%$ BSA in PBS. Plates were rinsed with wash buffer and 1:100 diluted serum samples were added (100 $\mu \mathrm{l} /$ well), followed by incubation for $1 \mathrm{~h}$ at room temperature. Plates were then washed and $100 \mu \mathrm{l} /$ well of the anti-IgM biotinylated detection antibodies 1:20,000 diluted in wash buffer were added for $1 \mathrm{~h}$ at room temperature. After that, plates were newly washed, 1:4000 wash buffer diluted streptavidinhorseadish peroxidase was added (100 $\mu \mathrm{l} /$ well), and the plates were incubated for $30 \mathrm{~min}$ at room temperature. Plates were then washed, $100 \mu \mathrm{l} /$ well of the $0.04 \%$ chromogen substrate OPD (o-phenylendiamide, Sigma) diluted in citrate buffer ( $\mathrm{pH} 5.0$ ) containing $0.02 \% 30 \mathrm{v} / \mathrm{v} \mathrm{H}_{2} \mathrm{O}_{2}$ was added, and the plates were incubated in the dark for $30 \mathrm{~min}$ at room temperature. The reaction was terminated with $50 \mu \mathrm{l} /$ well of $1 \mathrm{M} \mathrm{H}_{2} \mathrm{SO}_{4}$ solution. Plates were read at $492 \mathrm{~nm}$ in a spectrophotometer (E max-Molecular Devices). All samples were assayed in duplicate.

\subsection{Histology}

Hearts were removed at necropsy, and sections were immediately fixed in $10 \%$ phosphate-buffered formalin. After fixation, sections were prepared by standard methods for paraffin-embedded blocks, and cut sections were stained with hematoxylin and eosin. Cardiac parasitism and inflammation of ventricles were estimated in three different 7- $\mu \mathrm{m}$ depth sections in each heart, and five different animals were analyzed in each group. Amastigote nests and inflammation were assessed with a Zeiss (Öberkohen, Germany) integrating eyepiece, with 100 hits at a final magnification of 400×. A total of 3000 hits was evaluated in each section of cardiac tissue. The infection index represents the number of hits covered by amastigote nests, and the inflammatory index represents the number of hits in which inflammatory cells were present.

\subsection{Statistical analysis}

All results are presented as the mean \pm S.E.M. Normalized data were analyzed by one-way ANOVA and differences between groups were assessed using the Student-NewmanKeuls post-test. A value of $P<0.05$ was considered to be significant. All analyses were made using the INSTAT program (Graph PAD Software, Inc. San Diego, California).

\section{Results}

\subsection{Infection indices in T. cruzi-infected $P A F R^{-/-}$mice}

We have previously shown that blockade of PAFR with the PAFR antagonist WEB-2170 [2] or UK-74,505 (our own unpublished data) was associated with increased parasitemia

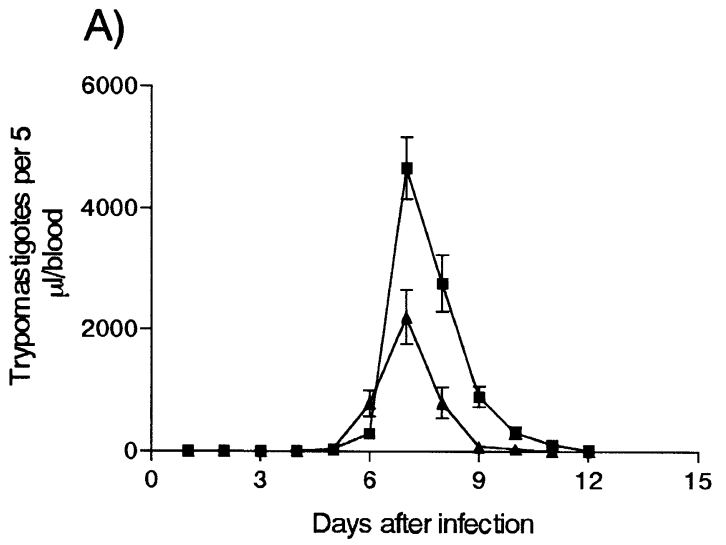

B)

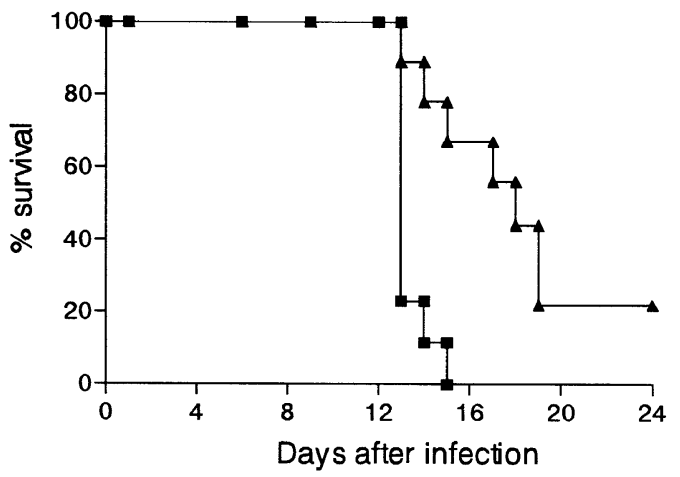

Fig. 1. Blood parasitemia (A) and lethality (B) during experimental T. cruzi infection in $\mathrm{PAFR}^{-/}$and wild-type mice. $\mathrm{PAFR}^{-/-}$(squares) and wild-type (triangles) mice were infected with $5 \times 10^{3}$ trypomastigote forms of $T$. cruzi intraperitoneally. Results are shown as the mean \pm S.E.M. of 10 mice per group in one of two independent experiments. The parasitemia and lethality curves of $\mathrm{PAFR}^{-/}$and wild type were significantly different $(P<0.01)$.

following infection with $5 \times 10^{3}$ T. cruzi trypomastigotes. Here, parasitemia in $\mathrm{PAFR}^{-/-}$mice was approximately twice that of C57BL/6 wild-type mice at the peak of parasitemia (Fig. 1A). More importantly, the survival of infected PAFR ${ }^{-/}$ mice was lower than that of infected wild-type mice (Fig. 1B). Indeed, $15 \mathrm{~d}$ after infection, none of the $\mathrm{PAFR}^{-1}$ mice, but around $70 \%$ of wild-type animals were alive (Fig. 1B).

\subsection{Pathological alterations in T. cruzi-infected $P A F R^{-/-}$ mice}

The morphological analysis of cardiac tissue of wild-type mice 10 and $15 \mathrm{~d}$ after infection showed few parasite nests scattered throughout the tissue (Fig. 2A). Parasite nests were already noticeable $10 \mathrm{~d}$ after infection only in $\mathrm{PAFR}^{-/}$mice (Fig. 2A). Albeit in small quantities, heart sections of $\mathrm{PAFR}^{-/-}$mice had three-fold more parasite nests than those of wild-type mice $15 \mathrm{~d}$ after infection (Fig. 2A). Heart inflammation was characterized by the presence of multiple inflammatory focci composed mainly of mononuclear cells and a diffuse mononuclear cell infiltrate. The inflammatory infiltrate was already present on day 10 after infection but was more marked on day 15 in wild-type mice (Fig. 2B). 
A)
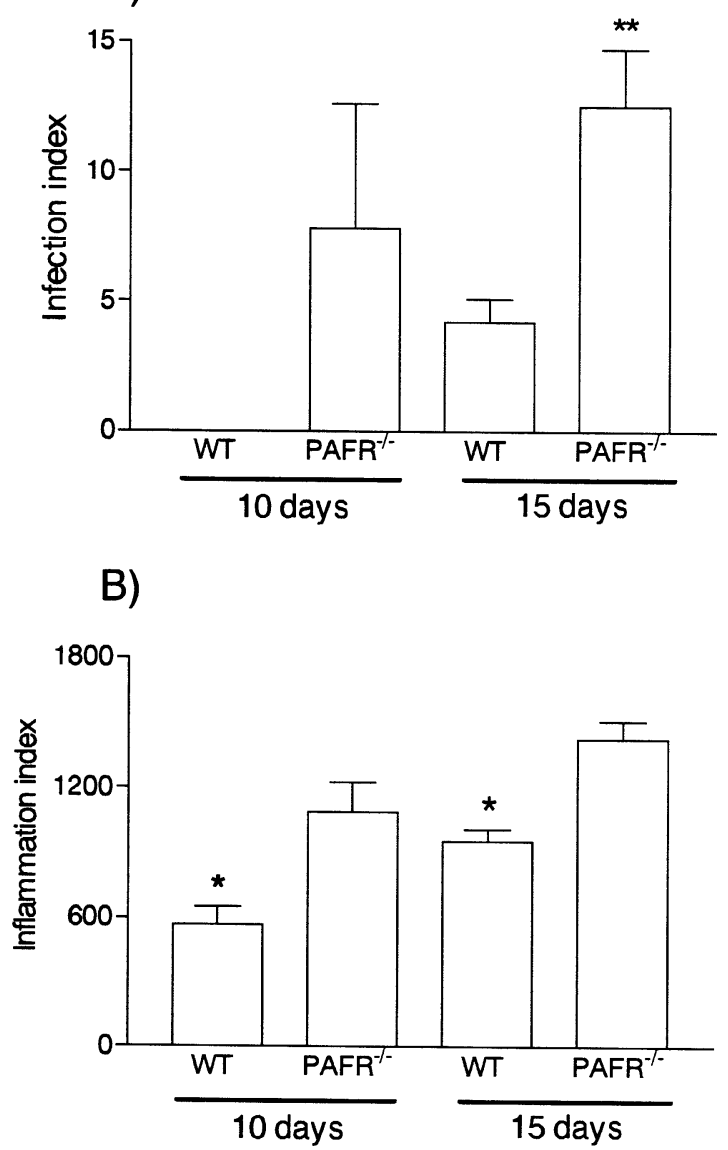

Fig. 2. Quantification of infection (A) and tissue inflammation (B) in $\mathrm{PAFR}^{--}$and wild-type mice. PAFR ${ }^{--}$and wild-type (WT) mice were infected with $5 \times 10^{3}$ trypomastigote forms of T. cruzi intraperitoneally, and inflammatory and parasitological indices were evaluated 10 and $15 \mathrm{~d}$ after infection. Results are shown as the mean \pm S.E.M. of five mice per group. * and $* *$ for $P<0.05$ and 0.01 , respectively, when compared with wild-type mice.

Tissue inflammation in heart sections of $\mathrm{PAFR}^{-/}$mice was of greater magnitude than that found in sections of hearts from wild-type mice (Fig. 2B).

\subsection{TNF- $\alpha, M C P-1$, RANTES and IFN- $\gamma$ synthesis in heart tissue T. cruzi-infected PAFR ${ }^{-/-}$mice}

The concentrations of TNF- $\alpha$ in serum of T. cruzi-infected wild-type and $\mathrm{PAFR}^{-1-}$ mice are shown in Fig. 3A. Concentrations of TNF- $\alpha$ in serum of PAFR ${ }^{-/}$mice were $28 \%$ lower than those of wild-type mice, but this difference failed to reach statistical significance $(P=0.06)$. TNF- $\alpha$ was not detected in serum of uninfected controls. Similarly, there was no significant difference between the concentration of nitrate and nitrite $\left(\mathrm{NO}_{x}\right)$ in serum samples of $\mathrm{PAFR}^{-/-}$and wild type after T. cruzi infection (Fig. 3B).

We have previously demonstrated the expression of TNF- $\alpha$, RANTES, MCP- 1 and IFN- $\gamma$ mRNA in cardiac tissue of mice following T. cruzi infection [11]. Here, the concentrations of TNF- $\alpha$, RANTES, MCP- 1 and IFN- $\gamma$ pro-
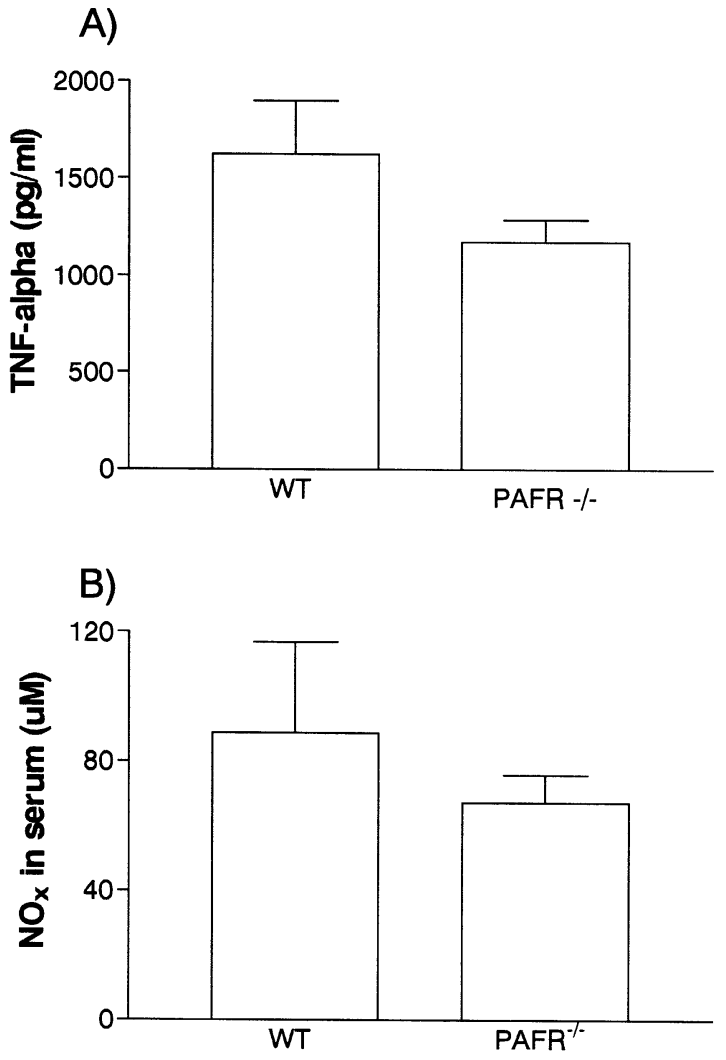

Fig. 3. Serum concentrations of TNF- $\alpha$ (A) and nitrate/nitrite (B) during experimental T. cruzi infection in $\mathrm{PAFR}^{-/}$and wild-type mice. $\mathrm{PAFR}^{-/}$and wild-type (WT) mice were infected with $5 \times 10^{3}$ trypomastigote forms of $T$. cruzi intraperitoneally, and serum concentrations of TNF- $\alpha$ and nitrate/nitrite $\left(\mathrm{NO}_{x}\right)$ were evaluated $10 \mathrm{~d}$ after infection. Results are shown as the mean \pm S.E.M. of five mice per group.

tein in heart tissues were detected using ELISA. Five days after infection, the concentration of TNF- $\alpha$ in infected mice was already elevated, and dropped to those found in uninfected controls by day 15 (Fig. 4A). The concentration of MCP-1 in infected wild-type mice was significantly greater than uninfected controls from day 5 and remained elevated throughout the 15-day observation period (Fig. 4B). The concentrations of TNF- $\alpha$ and MCP-1 in heart tissue of $\mathrm{PAFR}^{-/-}$mice were not different from those of infected wild-type mice (Fig. 4A,B). In contrast, there were some differences in the concentration of RANTES between the two groups. The RANTES concentration was higher than in uninfected controls only $10 \mathrm{~d}$ after infection, decreasing on day 15 (Fig. 4C). Ten days after infection RANTES protein expression was lower in $\mathrm{PAFR}^{-/}$than wild type. However, there was a $40 \%$ increase in the levels of RANTES in $\mathrm{PAFR}^{-1-}$ on day 15 (Fig. 4C). Concentrations of IFN- $\gamma$ in heart tissue of infected wild-type mice were elevated from days 5 through 15 after infection, although there was a tendency for IFN- $\gamma$ to drop on day 15 (Fig. 4D). The concentrations of IFN- $\gamma$ in $\mathrm{PAFR}^{-/}$mice were similar to those of wild-type controls at days 5 and 10 after infection and significantly greater on day 15 (Fig. 4D). 

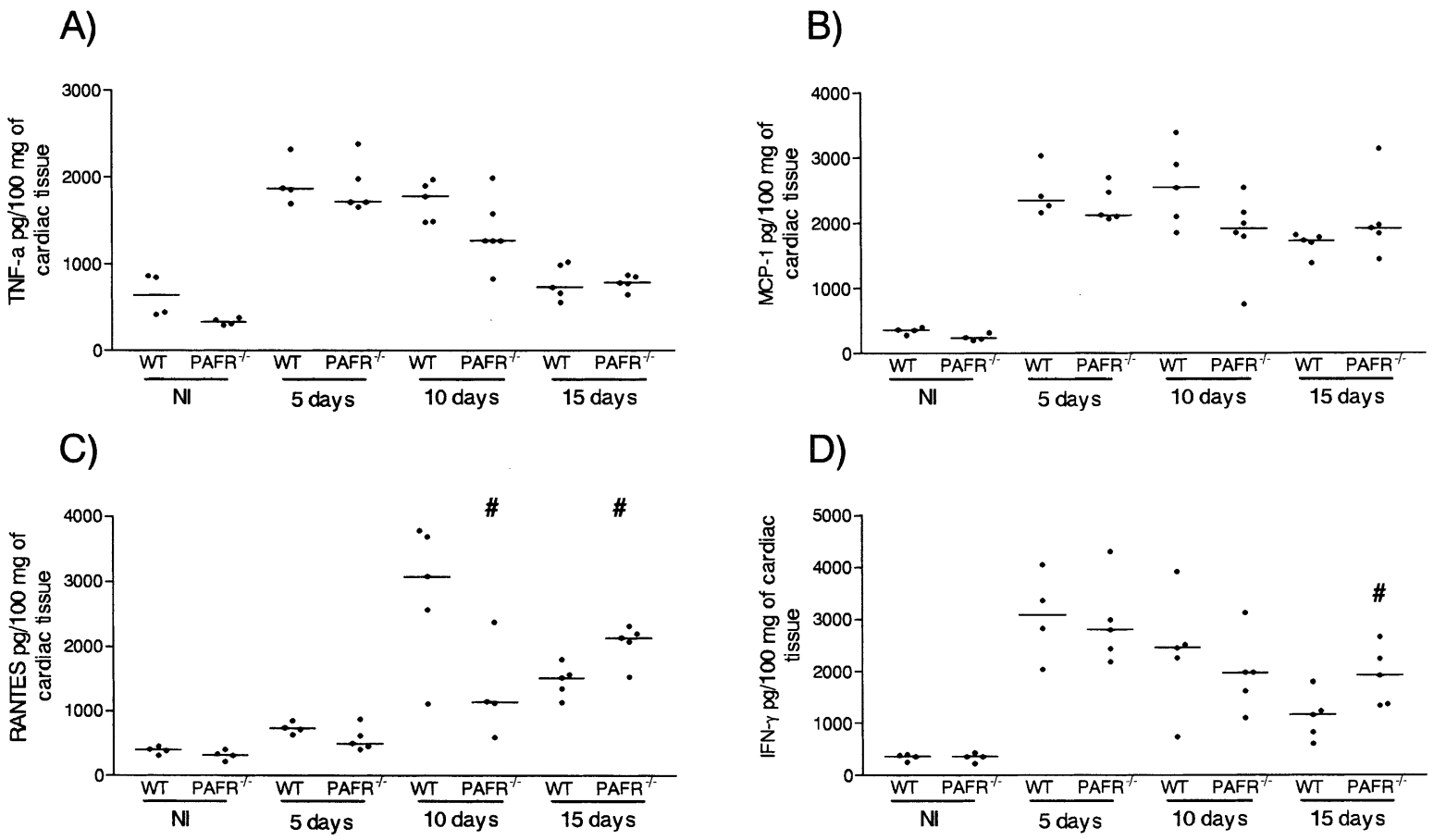

Fig. 4. Heart tissue concentrations of TNF- $\alpha$ (A), MCP-1 (B), RANTES (C) and IFN- $\gamma$ (D) during experimental T. cruzi infection in PAFR ${ }^{-/}$and wild-type mice. PAFR ${ }^{-1-}$ and wild-type (WT) mice were infected with $5 \times 10^{3}$ trypomastigote forms of $T$. cruzi intraperitoneally, and heart tissue concentrations of TNF- $\alpha$, MCP-1, RANTES and IFN- $\gamma$ were evaluated 5, 10 and $15 \mathrm{~d}$ after infection. Each dot represents the result in single animals, and the bar, the mean value. \# for $P<0.05$ when compared with respective wild-type controls.

\subsection{Titers of parasite-specific IgM}

In order to evaluate whether the deficiency in PAFR would be accompanied by an altered ability of the host to mount an effective humoral response, parasite-specific IgM was measured after $T$. cruzi infection in wild-type and $\mathrm{PAFR}^{-/}$mice. As clearly seen in Fig. 5, IgM was much greater in infected mice than in non-infected controls, but there was no significant alteration in the levels of this immunoglobulin between wild-type and $\mathrm{PAFR}^{-1-}$ mice.

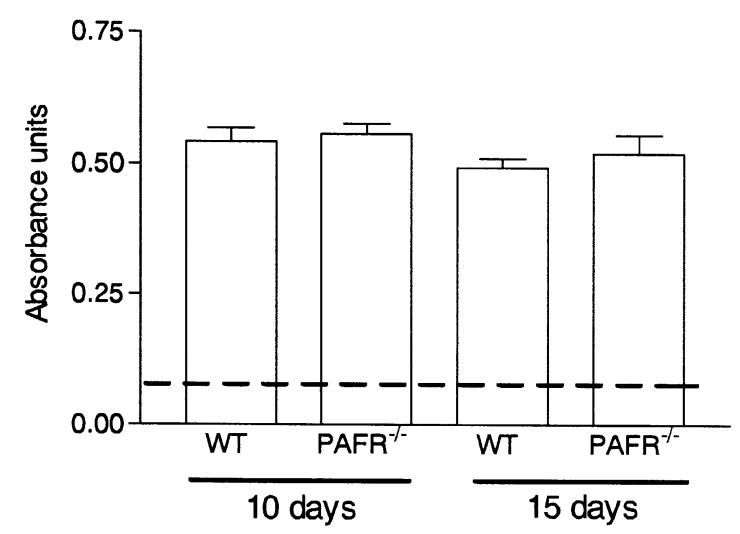

Fig. 5. Levels of parasite-specific IgM during experimental T. cruzi infection in $\mathrm{PAFR}^{-1-}$ and wild-type mice. $\mathrm{PAFR}^{--}$and wild-type (WT) mice were infected with $5 \times 10^{3}$ trypomastigote forms of $T$. cruzi intraperitoneally, and serum concentration of parasite-specific IgM (1/100 dilution) was evaluated 10 and $15 \mathrm{~d}$ after infection. The dotted line across the graph represents background levels of IgM in non-infected mice. Results are mean \pm S.E.M. of 3-4 mice per group.

\subsection{Defective parasite uptake in $P A F R^{-/}$mice}

The pretreatment of macrophages with PAF, $\mathrm{LTB}_{4}$ and MCP-1 is accompanied by an early (within $2 \mathrm{~h}$ ) increase in the uptake of parasites and a late (within $48 \mathrm{~h}$ ) activation of inducible nitric oxide synthase (iNOS) and NO-dependent parasite killing $[12,17,19]$. In our experiments, pretreatment of macrophages derived from wild-type mice with PAF, $\mathrm{LTB}_{4}$ or MCP-1 also induced a significant increase (1.5-fold increase of the basal uptake) in the early uptake of parasites (Fig. 6). In contrast, these agents failed to induce an increase in parasite uptake by macrophages derived from $\mathrm{PAFR}^{-/-}$ mice (Fig. 6).

\subsection{NO production by infected peritoneal macrophages}

Pretreatment with PAFR antagonists partially inhibits the production of NO by infected macrophages activated with IFN- $\gamma[12,19]$. Uninfected macrophages from wild-type and $\mathrm{PAFR}^{-/-}$mice did not produce detectable concentrations of NO. When these cells were infected with $T$. cruzi in the presence of IFN- $\gamma$, macrophages from wild-type mice produced greater levels of $\mathrm{NO}$ than macrophages from $\mathrm{PAFR}^{-/-}$ mice (infected wild-type macrophages + IFN- $\gamma, 46.1 \pm 3.0$ $\mu \mathrm{M}$ of nitrite; infected $\mathrm{PAFR}^{-/-}$macrophages $+\mathrm{IFN}-\gamma, 21.6 \pm$ $0.4 \mu \mathrm{M}, P<0.05)$.

\section{Discussion}

PAF, a membrane-derived phospholipid, is produced by a diversity of leukocytes and possesses widely recognized pro- 


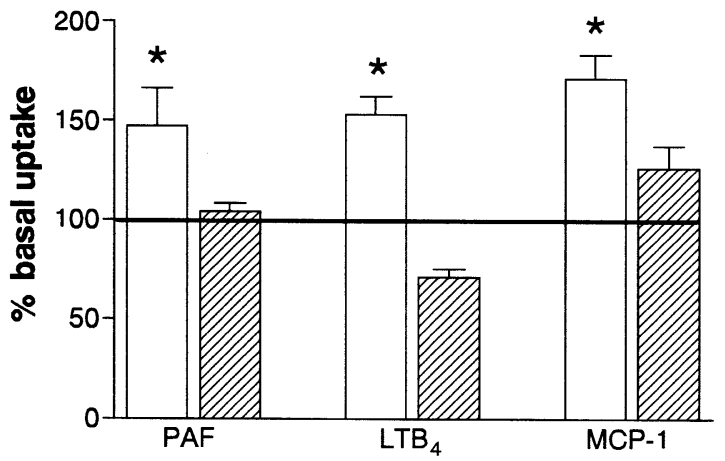

Fig. 6. T. cruzi trypomastigote uptake by macrophages in wild-type and $\mathrm{PAFR}^{-1-}$ mice. Thyoglicolate-induced macrophages from wild-type (open bars) or $\mathrm{PAFR}^{-/}$(hatched bars) mice were incubated with saline, $\mathrm{PAF}(1$ $\mu \mathrm{M}), \operatorname{LTB}_{4}(0.1 \mu \mathrm{M})$ or MCP-1 $(0.1 \mu \mathrm{M})$ for $10 \mathrm{~min}$ and then infected with $T$. cruzi in a 2:1 parasite:cell ratio. After $60 \mathrm{~min}$, the number of parasites inside 200 macrophages was evaluated. The line across the graph represents basal uptake of parasites ( $27 \pm 3$ parasites in 200 saline-treated macrophages) in saline-treated macrophages. Results are shown as the \% change from salinetreated animals, and are the mean \pm S.E.M. of triplicate determinations in at least two experiments. $*$ for $P<0.05$ when compared with saline-treated macrophages.

inflammatory activities $[14,15]$. Here, we aimed at evaluating a pathophysiological role for PAF receptor during experimental $T$. cruzi infection by using animals genetically deficient for this receptor [20]. We evaluated potential differences in cardiac tissue inflammation and parasitism and in the production of cytokines between wild-type and $\mathrm{PAFR}^{-/}$ C57BL/6 mice.

Our results show that $\mathrm{PAFR}^{-1}$ mice are more susceptible to T. cruzi infection than their wild-type controls. Thus, PAFR $^{-1-}$ mice infected with $T$. cruzi had at least twice the amount of parasites in blood at the peak of parasitemia. The latter results are in agreement with our previous studies with PAFR antagonists [19]. Despite the paucity of amastigote nests in heart tissues of infected mice, the present study showed that there was greater tissue parasitism in $\mathrm{PAFR}^{-/}$ than in wild-type mice. Overall, the above results suggest that PAFR plays a relevant role in controlling parasitemia and tissue parasitism. More importantly, the increased tissue and blood parasitism and tissue inflammation in $\mathrm{PAFR}^{-/-}$animals was associated with lower survival following $T$. cruzi infection. The mechanism of infection-associated death was not investigated here, but it is clearly correlated with the inability of the murine host to deal with $T$. cruzi infection.

The production of IFN- $\gamma$ by immune cells and the elevation of parasite-specific IgM are important immunological factors involved in host resistance to T. cruzi infection [5-8]. Thus, it was possible that a defective production of IFN- $\gamma$ or IgM could account for the inability of $\mathrm{PAFR}^{-/-}$mice to deal with T. cruzi infection. However, our results suggest that this may not be the case, as the expression of IFN- $\gamma$ in tissue and serum levels of IgM were similar in $\mathrm{PAFR}^{-/-}$and wild-type mice. Indeed, there was an even greater concentration of IFN- $\gamma$ in heart tissue of $\mathrm{PAFR}^{-/-}$mice at the later stages of the infection. Whether this simply reflects (or causes) the greater presence of inflammatory cell infiltrate or whether the lack of
PAFR facilitates the production of IFN- $\gamma$ was not investigated here.

Several studies have demonstrated a role of PAF and its receptor for the migration of leukocytes during acute and chronic inflammation [15,24-26]. These actions of PAFR may be via a direct action of PAF on the leukocyte inducing its direct recruitment or via the production of PAF-induced chemoattractant mediators, such as LTB $_{4}$ or IL-8 $[12,15,27]$. In $\mathrm{PAFR}^{-1-}$ mice, the greater intensity of tissue parasitism following $T$. cruzi infection was associated with a greater intensity of tissue inflammation. Thus, in contrast to other models of inflammation where PAF is relevant for the recruitment of inflammatory cells, it appears that activation of PAFR does not play a crucial role in the cascade of events that leads to the migration of leukocytes to heart tissue following $T$. cruzi infection in mice.

As tissue inflammation was enhanced in heart tissue of $\mathrm{PAFR}^{-1-}$ mice, it was of interest to examine whether there was an increase in the tissue levels of chemoattractants thought to be relevant during experimental $T$. cruzi infection [3]. To this end, we measured the levels of the chemokines RANTES and MCP-1 in heart tissue of infected wild-type and $\mathrm{PAFR}^{-/-}$mice from 5 to $15 \mathrm{~d}$ after infection. Message RNA for both chemokines has been detected in T. cruziinfected macrophages in vitro and in heart tissue following experimental infection in mice $[11,17,28]$. In addition, we have recently shown that MCP-1 release accounts for the ability of glycosylphosphatidylinositol-anchored mucin-like glycoproteins present on trypomastigotes to induce leukocyte recruitment in IFN- $\gamma$-primed mice [9]. MCP-1 was produced throughout the course of the infection, and no significant differences could be observed between wild-type and $\mathrm{PAFR}^{--}$mice. There was also significant expression of RANTES, especially after the 10th day of infection. In $\mathrm{PAFR}^{-/-}$mice, the levels of RANTES were lower than in controls on day 10 and higher on day 15. As heart tissue inflammation in $\mathrm{PAFR}^{-/}$mice was already greater than controls on day 10 , it is unlikely that RANTES would explain the greater tissue inflammation observed in these animals. However, the elevated levels of this chemokine in the later stages of infection (day 15) could be a contributing factor to the greater infiltration of leukocytes at a later stage. Interestingly, there was a good correlation between the expression of RANTES and IFN- $\gamma$ in heart tissue in wild-type and PAFR ${ }^{--}$ mice. In the latter group of animals, the increase in RANTES on day 15 above levels in infected wild-type mice was mirrored by an increased expression of IFN- $\gamma$. This is in agreement with our previous studies and suggestion that IFN- $\gamma$ is a major regulator of RANTES and other chemokines during experimental T. cruzi pathology [3,11].

As inhibition of chemoattractant production and the influx of leukocytes did not appear to account for the worsening of experimental T. cruzi infection, we then evaluated whether the activation of PAFR was relevant for the production of TNF- $\alpha$ and NO, as we have previously demonstrated in vitro $[12,19]$. The concentration of $\mathrm{NO}_{2} / \mathrm{NO}_{3}$ in plasma of infected 
wild-type and $\mathrm{PAFR}^{-/}$mice was not significantly different. Similarly, there was no marked difference in concentration of TNF- $\alpha$ in plasma of PAFR $^{-/-}$and wild-type mice. High levels of TNF- $\alpha$ were measured in heart tissue from the 5 th to the 15 th day of infection, in agreement with the ability of infected macrophages and cardiomyocytes to produced this cytokine [29]. Again, no differences were observed between wild-type and $\mathrm{PAFR}^{-1-}$ mice. Thus, whereas PAFR may be relevant for the ability of infected macrophages to produce TNF- $\alpha$ in vitro, this receptor does not have any marked influence on the production of TNF- $\alpha$ when evaluated in the whole extract of the heart or in plasma.

The addition of chemoattractant mediators-including PAF, $\mathrm{LTB}_{4}$ and MCP-1-to T. cruzi-infected peritonealderived macrophages induced the production of $\mathrm{NO}$ and NO-dependent killing [12,17,19]. NO production was greatly associated with an early increase in parasite uptake and a late activation of iNOS $[12,17,19]$. Preliminary studies from our laboratory suggest that chemoattractant-induced increase in parasite uptake appears to be secondary to the ability of these molecules to induce the phagocytosis of the parasite by macrophages (Santana et al., in preparation). Thus, whereas basal uptake of $T$. cruzi by macrophages was largely phagocytosis independent, chemoattractants enhanced parasite uptake through a mechanism suppressed by drugs that prevented phagocytosis. Importantly, the enhanced uptake of $T$. cruzi by macrophages was accompanied by enhanced NO production and NO-dependent killing $[12,17,19]$. Here, pretreatment of macrophages with PAF, $\mathrm{LTB}_{4}$ or MCP-1 enhanced parasite uptake in wild-type but not in $\mathrm{PAFR}^{--}$mice. Of interest, PAF may not only act on surface receptors but also on nuclear PAFR to induce gene transcription and leukocyte activation [30], suggesting that measurement of PAF on supernatants is not useful, especially when there is a marked functional phenotype induced by PAFR antagonists or in gene-deficient mice. This is a situation similar to the necessary role of PAFR for the ability of neutrophils to phagocytose zymosan [27]. Overall, these results argue for an important role of PAFR in mediating uptake of T. cruzi parasites, possibly via facilitation of the expression of integrins [27] and phagocytosis. As enhanced early $T$. cruzi uptake is associated with enhanced NOdependent killing at a later stage, it is possible that the greater tissue and blood parasitism observed in $\mathrm{PAFR}^{-/-}$mice may be secondary to the inability of tissue macrophages to deal with $T$. cruzi infection in vivo. In addition, IFN- $\gamma$-induced NO production was also partially dependent on the activation of PAFR, as demonstrated by experiments with PAFR antagonists [12,19] and $\mathrm{PAFR}^{-/-}$mice (shown here).

Thus, a situation may arise where, although present in sufficient numbers, macrophages may be unable to deal with infection, as they are not capable of phagocytosing and do not produce the necessary molecules, such as NO, to kill the parasite. The reason why macrophages treated with PAFR antagonists or those derived from $\mathrm{PAFR}^{-1}$ mice have defective NO production in the presence of IFN- $\gamma$ is unknown.
Nevertheless, our data suggest that the role of PAF during $T$. cruzi infection may stem from the role of this mediator in promoting phagocytosis of the parasite particle and subsequent production of effector molecules, such as NO. Further studies are necessary to evaluate the role of this lipid mediator for $T$. cruzi in other species and in humans.

\section{Acknowledgements}

This work was supported by Fundação Amparo a Pesquisas do Estado de Minas Gerais (FAPEMIG), Comissão Aperfeiçoamento Pessoal Ensino Superior (CAPES) and Conselho Nacional Desenvolvimento Científico de Tecnológico (CNPq). We are grateful to Dr. Fernando Cunha for performing the nitrate measurements and Dr. Elizabeth Camargos for helping with the morphometric analysis.

\section{References}

[1] J.C. Dias, Chagas'disease. Epidemiology and prevention, Arq. Bras. Cardiol. 63 (1994) 451-455.

[2] G.F. Mendez, M.R. Cowie, The epidemiological features of heart failure in developing countries: a review of the literature, Int. J. Cardiol. 80 (2001) 213-219.

[3] M.M. Teixeira, R.T. Gazzinelli, J.S. Silva, Chemokines, inflammation and Trypanosoma cruzi infection, Trends Parasitol 18 (2002) 262-265.

[4] M.M. Teixeira, I.C. Almeida, R.T. Gazzinelli, Introduction: innate recognition of bacteria and protozoan parasites, Microb. Infect. 4 (2002) 883-886.

[5] D.M. Engman, J.S. Leon, Pathogenesis of Chagas disease heart disease: role of autoimmunity, Acta Trop. 81 (2002) 123-132.

[6] M.B. Soares, L. Pontes-De-Carvalho, R. Ribeiro-Dos-Santos, The pathogenesis of Chagas' disease: when autoimmune and parasitespecific immune responses meet, An. Acad. Bras. Cienc. 73 (2001) 547-559.

[7] L. Pontes-de-Carvalho, C.C. Santana, M.B. Soares, G.G. Oliveira, E. Cunha-Neto, R. Ribeiro-Dos-Santos, Experimental chronic Chagas' disease myocarditis is an autoimmune disease preventable by induction of immunological tolerance to myocardial antigens, J. Autoimmun. 18 (2002) 131-138.

[8] Z. Brener, R.T. Gazzinelli, Immunological control of Trypanosoma cruzi infection and pathogenesis of Chagas' disease, Int. Arch. Allergy Immunol. 114 (1997) 103-110.

[9] P.S. Coelho, A. Klein, A. Talvani, S.F. Coutinho, O. Takeuchi, S. Akira, J.S. Silva, H. Canizzarro, R.T. Gazzinelli, M.M. Teixeira, Glycosylphosphatidylinositol-anchored mucin-like glycoproteins isolated from Trypanosoma cruzi trypamastigotes induce in vivo leukocyte recruitment dependent on MCP-1 production by IFN- $\gamma$ primed-macrophages, J. Leuk. Biol. 71 (2002) 837-844.

[10] P.V. dos Santos, E. Roffe, H.C. Santiago, R.A. Torres, A.P. Marino, C.N. Paiva, A.A. Silva, R.T. Gazzinelli, J. Lannes-Vieira, Prevalence of CD8 (+) alpha beta T cells in Trypanosoma cruzi-elicited myocardites is associated with acquisition of CD62L (low) LFA-1 (high) VLA-4 (high) activation phenotype and expression of IFN-gammainducible adhesion and chemoattractant molecules, Microb. Infect. 3 (2001) 971-984. 
[11] A. Talvani, C.S. Ribeiro, J.C.S. Aliberti, V. Michailowsky, P.V. Santos, S.M. Murta, A.J. Romanha, I.C. Almeida, J. Farber, J. Lannes-Vieira, J.S. Silva, R.T. Gazzinelli, Kinetics of cytokine gene expression in experimental chagasic cardiomyopathy: tissue parasitism and endogenous IFN-gamma as important determinants of chemokine mRNAs expression during infection with Trypanosoma cruzi, Microb. Infect. 2 (2000) 851-866.

[12] A. Talvani, F.S. Machado, G. Santana, A. Klein, L.S. Barcelos, J.S. Silva, M.M. Teixeira, Leukotriene $\mathrm{B}_{4}$ induces nitric oxide synthesis in Trypanosoma cruzi-infected murine macrophages and mediates resistance to infection, Infect. Immun. 70 (2002) 4247-4253.

[13] F. Villalta, Y. Zhang, K. Bibb, J.C. Kappes, M.F. Lima, The cysteinecysteine family of chemokines RANTES, MIP-1 alpha and MIP-1 beta induce trypanocidal activity in human macrophages via nitric oxide, Infect. Immun. 66 (1998) 4690-4695.

[14] P. Braquet, L. Touqui, T.Y. Shen, B.B. Vargaftig, Perspectives in platelet-activating factor research, Pharmacol. Rev. 39 (1987) 97-145.

[15] G. Montrucchio, G. Alloatti, G. Camussi, Role of platelet-activating factor in vascular cardiovascular pathophysiology, Physiol. Rev. 80 (2000) 1669-1699.

[16] A. Klein, V. Pinho, A.L. Alessandrini, T. Shimizu, S. Ishii, M.M. Teixeira, Platelet-activating factor drives eotaxin production in an allergic pleurisy in mice, Br. J. Pharmacol. 135 (2002) 1213-1218.

[17] J.C.S. Aliberti, F.S. Machado, J.T. Souto, A.P. Campanelli, M.M. Teixeira, R.T. Gazzinelli, J.S. Silva, $\beta$-chemokines enhance parasite uptake and promote nitric oxide-dependent microbiostatic activity in murine inflammatory macrophages infected with Trypanosoma cruzi, Infect. Immun. 67 (1999) 4819-4826.

[18] G.A. Martins, L.Q. Vieira, F.Q. Cunha, J.S. Silva, Gamma Interferon modulates CD95 (Fas) and CD95 ligand (Fas-L) expression and nitric oxide-induced apoptosis during the acute phase of Trypanosoma cruzi infection: a possible role in immune response control, Infect. Immun. 67 (1999) 3864-3871.

[19] J.C.S. Aliberti, F.S. Machado, R.T. Gazzinelli, M.M. Teixeira, J.S. Silva, Platelet-activating factor induces nitric oxide synthesis in Trypanosoma cruzi-infected macrophages and mediates resistance to parasite infection in mice, Infect. Immun. 67 (1999b) 2810-2814.

[20] S. Ishii, T. Shimizu, Platelet-activating factor (PAF) receptor and genetically engineered PAF receptor mutant mice, Prog. Lipid. Res. 39 (2000) 41-82.
[21] R.C. Melo, Z. Brener, Tissue tropism of different Trypanosoma cruzi strains, J. Parasitol. 64 (1978) 475-482.

[22] G.N.R. Vespa, F.Q. Cunha, J.S. Silva, Nitric oxide is involved in control of Trypanosoma cruzi-induced parasitemia and directly kills the parasite in vitro, Infect. Immun. 62 (1994) 5177-5182.

[23] B.M. Tavares-Murta, M. Zaparoli, R.B. Ferreira, M.L. Silva-Vergara, C.H. Oliveira, E.F. Murta, S.H. Ferreira, F.Q. Cunha, Failure of neutrophil chemotactic function in septic patients, Crit. Care Med. 30 (2002) 1056-1061.

[24] J.R. Jackson, B. Bolognese, C.A. Mangar, W.C. Hubbard, L.A. Marshall, J.D. Winkler, The role of platelet activating factor and other lipid mediators in inflammatory angiogenesis, Biochim. Biophys. Acta 1392 (1998) 145-152.

[25] Z. Honda, S. Ishii, T. Shimizu, Platelet-activating factor receptor, J. Biochem. 131 (2002) 773-779.

[26] D.G. Souza, D.C. Cara, G.D. Cassali, S.F. Coutinho, M.R. Silveira, S.P. Andrade, S. Poole, M.M. Teixeira, Effects of the PAF receptor antagonist UK74505 on local and remote reperfusion injuries following ischemia of the superior mesenteric artery in the rat, $\mathrm{Br}$. J. Pharmacol. 131 (2000) 1800-1808.

[27] B.T. Au, M.M. Teixeira, P.D. Collins, T.J. Williams, Blockade of PAF receptors controls IL-8 production by regulating the activation of neutrophil CD11/CD18, Eur. J. Pharmacol. 425 (2001) 65-71.

[28] J.C.S. Aliberti, J.T. Souto, A.P.M. Marino, J. Lannes-Vieira, M.M. Teixeira, J. Farber, R.T. Gazzinelli, J.S. Silva, Modulation of chemokine production and inflammatory responses in interferon- $\gamma$ and tumor necrosis factor-R1-deficient mice during Trypanosoma cruzi infection, Am. J. Pathol. 158 (2001) 1433-1440.

[29] F.S. Machado, G.A. Martins, J.C.S. Aliberti, F.L.A.C. Mestriner, F.Q. Cunha, J.S. Silva, Trypanosoma cruzi-infected cardiomyocytes produce chemokines and cytokines that trigger potent nitric oxidedependent Trypanocidal activity, Circulation 102 (2000) 3003-3008.

[30] A.M. Marrache, F. Gobeil Jr., S.G. Bernier, J. Stankova, M. RolaPleszczynski, S. Choufani, G. Bkaily, A. Bourdeau, M.G. Sirois, A. Vazquez-Tello, L. Fan, J.S. Joyal, J.G. Filep, D.R. Varma, A. Ribeiro-Da-Silva, S. Chemtob, Proinflammatory gene induction by platelet-activating factor mediated via its cognate nuclear receptor, J. Immunol. 169 (2002) 6474-6481. 